\title{
BIOMETRIC INVESTIGATION OF HUMAN- AND VETERINARY- BIOLOGICAL EFFECTS OF ELECTROMAGNETIC FIELDS
}

\author{
L. BÖRZSÖNYI ${ }^{1 *}$-SZABÓ F. ${ }^{2}$-BECKERS J. F. ${ }^{3}$-SULON J. ${ }^{3}$-FODOR J. ${ }^{1}$-SZENCI O. ${ }^{2}$ \\ *e-mail: Borzsonyi.Laszlo@aotk.szie.hu \\ ${ }^{I}$ Department of Biomathematics and Informatics, Faculty of Veterinary Science, \\ Szent István University of Budapest \\ H-1078 Budapest, István u. 2, Hungary \\ (phone: +36-1-478-4212; fax: +36-1-478-4217) \\ ${ }^{2}$ Clinic for Large Animals, Faculty of Veterinary Science, \\ Szent István University of Budapest \\ H-2225 Üllö, Hungary \\ (phone: +36-29-521-300; fax: +36-29-521-303) \\ ${ }^{3}$ Department of Physiology of Reproduction, Faculty of Veterinary Medicine, University of \\ Liege, Bd de Colonster No20, P71, Bat. B41, B-400 Sart-Tilman, Belgium \\ (phone. +32-43664161; fax: $+32-477297018$ ) \\ (Received $10^{\text {th }}$ Sep 2005 , accepted $10^{\text {th }}$ Oct 2006)
}

\begin{abstract}
In our days attention has been focused on the analysis of the effects of electromagnetic fields both in human and veterinary medicine. The significance of analyses has been underlined by both therapeutic and noxions effects of magnetic field therapies to the living organism. Due to the fact that modern technical devices are widely used, the phenomena and data observed in connection with their use urge exact evaluation and analysis.

The exact effect mechanism of electromagnetic field therapies is not quite clear. The oxygen uptake of cells is supposedly increased by the induced magnetic field [18]. Electromagnetic field therapies in human and veterinary medicine are primarily used for treating soft tissue lesions [8], and bone and joint disorders [9]. There are some new investigations trying to explain the effects of the treatments for positive and negative stress sensibility. In the first part of our study the therapeutic and noxious effects observed in human and veterinary biology are summarised without aiming at completeness. In the second part the effect of magnetic field therapy in horses is thoroughly examined. The local effects of electromagnetic field treatments as well as the biological effects of electromagnetic therapy using magnetic blanket on blood gas and biochemical parameters are tested. Paired t-test was applied in the course of biometric evaluations.

The description of blood gas and acid-base parameters may it possible to apply magnetic field therapies for healing purpose as well as prevent stress-related diseases in race horses. The results of our investigation might lead to the conclusion that they are adaptable in human medicine as well.

Keywords: magnetic protection of the environment magnetic field therapy, electrosmog, blood gas parameters, paired t-test, error of first kind.
\end{abstract}

\section{Introduction}

The investigation of magnetic field effects goes back to a long history. There are records about the use of magnetic bars for therapeutic purposes in the territory of today's Turkey as early as 1000 B.C. [7]. There were written documents about the effects of magnetic field treatments in human medicine as early as the XVth century. The analysis of magnetic field effects and therapy has been in the forefront of 
investigations first in human then in veterinary medicine since the 1990-es [2]. It has been proved unambiguously that certain magnetic field therapies have healing, some others noxious effects on the living organism. When we use modern technical devices today, such questions are naturally raised: Do the single devices have deleterious effects on the environment and the living organism? How should we use these devices adequately? It is also a fact that in several cases it is not easy to demonstrate explicitly the deleterious effect of certain magnetic field on the environment, and we can conclude only from representative statistical figures that the diseases occuring significantly more frequently might be attributed to some magnetic field effect in the background [3].

It is reasonable to examine the electromagnetic protection of the environment from two aspects. We should focus partly on the biological effects, partly on electromagnetic compatibility. Electromagnetic compatibility means the ability of a device to operate adequately in an electromagnetic environment without causing intolerable inconveniences in the operation of another device [22]. In other words, its potential jamming-stability is sufficiently large- its jamming-emission is tolerably small. Concerning electromagnetic field effects, the jamming may originate from external and internal sources. An internal source means that the device jams itself. The external source of jamming may be artificial (e.g.: caused by human) or natural (e.g.: cosmic radiation, lightning). The jamming caused by humans may be directed (e.g.: radiofrequency radiation) or non-directed resulting from the side effect of an operating device (e.g.: neon tube). The time aspects of the jamming may be permanent/continuous or temporary. In case of permanent/continuous jamming the frequency spectrum is given, which may be periodic and non-periodic. With directed permanent/continuous periodic jamming we speak about linear-, with non-periodic jamming permanent/continuous Fourier spectrum. The frequency ranges of electromagnetic radiation are shown in Fig. 1, those of electromagnetic inconveniences in Fig. 2.

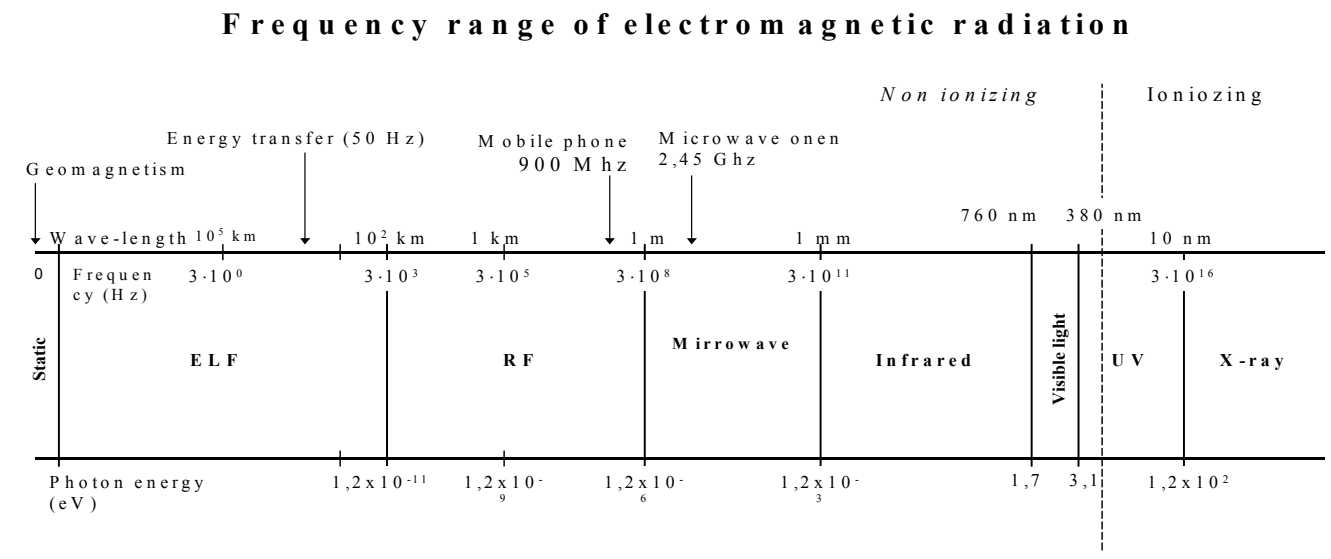

Figure 1. Frequency range of electromagnetic radiation [22] 


\section{Frequency ranges of elektromagnetic inconveniencies}

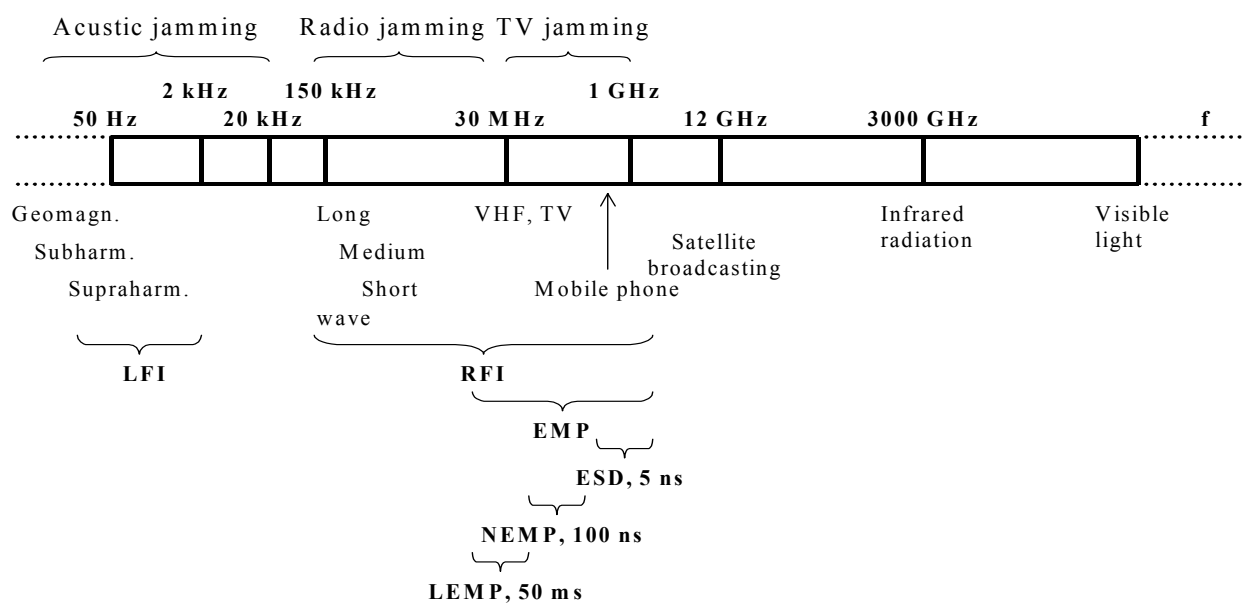

Figure 2. Frequency range of electromagnetic inconveniences [22]

Electromagnetic inconveniences may spread via radiation, wires, coupling or other ways. The most significant factor in the defence against the inconvenient electromagnetic effects is the recognition in time of the noxious effect and then the compensation or termination of it.

There are several observations reporting on the noxious and therapeutic effects on the living organism of electromagnetic fields. Thus it is comprehensible that electromagnetic protection of the environment as a new problem has been added to the long-existing, well-known problems of environmental protection.

\section{Human-related noxious effects of electromagnetic fields}

The collective name for electromagnetic effects noxious to living human organisms is electrosmog. Electrosmog is a scientifically based, biologically acting environmental factor, which occurs as a secondary product of electromagnetic fields and radiations as soon as it gets connected with living organisms. Human organisms give individual responses to the various electromagnetic effects and electrosmog. There are pronouncedly electrosensible people to electrosmog. Observations confirm that the effects of electromagnetic field are the most noxious with women in the period of menopause due to the change of the hormonal activity, and with children up to the age of approximately 13 due to the higher water content of their bodies. When electrosmog has noxious effects, the general, most frequently occuring disorders, the effects influencing blood circulation and the nervous system may be classified [19].

\section{The most frequently occuring symptoms}

General exertion, depression, weariness, headache, tinnitus, rapid asthenopia, temporary diplopia, smarting of the eyes, vertigo, weakening of concentration, forgetfulness, rapid aging, loss of skin flexibility, vibration (permanent electric charge) of one's hair, typical nasty taste in the mouth (metallic fillings, implantations), 
arthralgia, frequent spasms in the hands and feet, gastralgia, faeces irregularity (diarrhea, constipation) [19].

\section{Effects influencing blood circulation}

Unsteady blood pressure (fluctuations), rapidly developing high blood pressure, tachycardia, high pulse rate, disorder of the heart rhythm, ECG alterations, and blood picture alterations[20].

\section{Effects influencing the nervous system}

Sleep disorders, nervousness, EEG alterations, and disorder of the central nervous system, tinnitus, head-noises, and complete nervous breakdown [19].

Beside this, gradual progress in the impairment of the immune system is observable as a result of electrosmog.

\section{Human-related therapeutic effects of electromagnetic fields}

Electromagnetic effects of adequate intensity are widely used in therapeutics. The latest applications: microwave ballon therapy for dilating sclerotic bloodvessels and coronary arteries; microwave thermography for discovering tumors and blood circulation disorders; microwave hyperthermia for destroying cancerous tissues combined with medicinal treatment; rapid warming-up treatment: it is based on the thermis effect of microwave radiation, e.g.: refrigerated blood, warming-up of organs coming from the organ-bank prior to transplantation; etc [10], [12].

\section{Deleterious effects of electromagnetic field in veterinary medicine}

It is easy to understand that there are fewer noxious effects of electromagnetic field observed in veterinary science but there, too, are some striking examples. Calves born in the vicinity of a TV transmission tower had frequent physical deformities [20]. Newborn calves: two thoracic legs tilted backwards at the hooves (unability to walk); born with two heads (non-viable); born with six legs (on the back +two legs). The cattle-shed was within a radius of 150 meters in each case [4], [20].

An experiment was conducted with hen's eggs during the embryonic development. A treated and a control group were selected at random from an identical population. The treated group was radiated with electromagnetic field of $1 \mathrm{kHz}$ modulated between 0,9 $\mathrm{mW} / \mathrm{cm}^{2}-1,25 \mathrm{GHz}$. The hatched chickens showed signs of abnormal deformities. Spastic toes, double beak, typical deformities on the legs and eyes (limited eyesight, inability to walk) [5], [20].

Telstra (an Australian Telephone Company) irradiated 100 mice with a mobile phone in operation 2X30 minutes daily over a period of 18 months and compared them with a control group of 100 untreated mice. The occurence of lymphadenoma was significantly higher (twice as much) in the treated group [17], [20].

\section{Therapeutic effects of electromegnetic field observed in veterinary medicine}

The number of applied healing therapy with electromagnetic field is low but increasing in number. In an experiment a control and a treated group of aged male rats were selected at random from a population of the same age. The testis of the rats in the treated group was irradiated with infrared lamp for some time. The rats of the treated group turned out to show significantly higher $(\mathrm{p}<0,001)$ sexual activity. 


\section{Hazards of modern technical devices and their appropriate use}

Nowadays nearly all households use TVs, microwave ovens, monitors (joined to computers), night current, radio-alarm clocks, magnetic door opener, and mobile phones as means of personal communication. Their use is not without dangers. The use of a device results in the appearance of a so-called „radiating field" [20]. The appearing electrosmog decreases with the distance from the device growing. Thus, adequate environmental protection may lead to the termination or significant decrease in the noxiousness. A few practical instructions to the adequate use of the devices:

- An operating TV should be watched from a distance seven times the length of the screen diameter.

- You should be standing at least one meter away from the operating microwave oven and definitely not look into the oven (it might cause cataract formation in the eye) [5].

- Computer monitors emit electromagnetic and electrostatic radiation noxious to health. The top legible line of the screen should be at eye level so that the lower parts of the body get a lower amount of radiation. When it is used over a long period it is recommended to make 5-10 minute pauses to rest the eyes. Never keep your head too close to the screen. Statistical figures show that three out of ten monitors irradiate over the permissible limit [12], [22].

- The radio-alarm clock should be kept at a distance of at least 1.5 meters from the head.

- The mobile phone should be kept in the bag rather than in the pocket close to the body. It definitely weakens the immune system and might promote the development of thymus cancer and lymphadenoma [1], [20]!

- The magnetic door opener should not be keep next to the mobile phone. The battery of the mobile phone will go flat in a short time.

- The bed should be place far from the halogen lamp converter and the night current receiver [15].

\section{Materials and methods}

\section{Effects of electromagnetic field therapy on horses}

\section{Testing local effects of electromagnetic therapy in horses}

The following experiment was performed with 10 horses. Magnetic wraps were placed on tarsal and metatarsal region of right and left hind limbs of the horses and they were exposed to magnetic field therapy. Blood was withdrawn from each horse five times from v. saphena and a. metatarsalis:

- Sample 1: control (state prior to treatment)

- Sample 2: Thermic $\mathrm{T}_{0}$ (placement of magnetic wraps for 16 minutes without applying magnetic field treatment)

- Sample 3: Magnetic $\mathrm{T}_{0}$ (Magnetic wraps were taken off, followed by a 15minute pause, the magnetic wraps were placed back and magnetic field treatment was applied for 16 minutes and finally blood was with drawn) 
- Sample 4: Magnetic $T_{1}$ (Magnetic wraps were taken off, blood was withdrawn 15 minutes later)

- Sample 5: Magnetic $\mathrm{T}_{2}$ (blood was withdrawn again 30 minutes after the magnetic field treatment)

The body temperature of animals as well as the blood gas and acid-base parameters $(\mathrm{pH}$, pCO2, pO2, $\mathrm{HCO} 3, \mathrm{TCO} 2, \mathrm{ABE}, \mathrm{SBE}, \mathrm{SBC}, \mathrm{SAT}$ ) of the with drawn arterial and venous blood were measured [3]. Paired sample t-test was used to specify the significant deviations between the treated and control groups.

\section{Testing the effects of electromagnetic blanket in horses}

Healthy horses of different sexes and ages $(n=11)$ were investigated with regard to the effects of magnetic blanket on the physical and blood gas and acid-base parameters of the horses. Cannula was inserted in the arteria facialis of the horses and blood was withdrawn from each of them at 8 predetermined points of time.

- Sample 1: Control (state prior to treatment).

- Sample 2: 20 minutes later the horses got in a state of stress (excitation, pinching about).

- Sample 3: Right after 5 minutes' trotting blood was withdrawn.

- Sample 4: Following a 15-minute rest blood was withdrawn again

- Sample 5: The magnetic blanket was placed on for 16 minutes but the electric source was not turned on.

- Sample 6: The blanket was taken off and 15 minutes later blood was withdrawn.

- Sample 7: The blanket was placed on again, and was made to operate with full intensity for 16 minutes. Right after this blood was withdrawn.

- Sample 8: The blanket was taken off, the horses had a 15-minute rest, and then blood was withdrawn.

The horses' pulse rate, respiration rate and temperature values as well as the blood gas and acid-base parameters $(\mathrm{pH}, \mathrm{pCO} 2, \mathrm{pO} 2, \mathrm{HCO} 3, \mathrm{SAT})$ were determined in each case. The change in the horses'state of stress in relation to the control and certain stress phases was tested using paired t-test. To be exact, the following samples were involved in the comparison:

- I. $\quad 1$ - 2 control and state of stress

- II. $1-3$ control and trotting following the stress

- $\quad$ III. $2-3$ stress and trotting

- IV. 3-4 trotting and rest

- V. 4-5 rest and magnetic blanket on without electric source

- VI. 5-6 magnetic blanket on without electric source turned on and rest

- VII. 6-7 before and after turning on the magnetic blanket

- VIII. 7-8 magnetic field treatment and rest following it

\section{Effect of electromagnetic blanket on the biochemical parameters}

We conducted an experiment on 11 horses for 5 days in order to get data about LDH, AST and CK biochemical parameters by providing 16-minute treatments after putting 
on the magnetic blanket and withdrawn blood right before and after the treatment. Our observations were evaluated by paired sample t-test.

\section{Results and analyses}

\section{Local effects of electromagnetic field therapy in horses}

The results have been summarised in Table 1. Table 1 demonstrates that the results of arterial and venous tests differ from one another. The state right after the magnetic field therapy (Magnetic $\mathrm{T}_{0}$ ) shows significant deviation compared to the control group in almost all the parameters (except for pO2 and SAT). Evaluating arterial and venous tests we can conclude that the test results of arterial blood reflected the effects of the treatment more sensibly. The question is: What can be the explanation of it? In Table 1 it is also observable that $\mathrm{ABE}, \mathrm{SBE}$ and $\mathrm{SBC}$ parameters show significant deviation, as compared to the control, 15 minutes after the magnetic field therapy, and so do pCO2, pO2, HCO3 és TCO2 parameters after another 15 minutes. The probable conclusion from it is that magnetic field therapies have protracted effects and thus the changes of certain parameters get manifested somewhat later.

Table 1. Results of the local effects of electromagnetic field therapy in horses based on the comparison between the control and treated groups, where ns=non significant and tend=tendency.

\begin{tabular}{|c|c|c|c|c|c|c|c|c|c|c|}
\hline Test & \multicolumn{10}{|c|}{ Arterial $(\mathbf{p}<)$} \\
\hline & Temp. & pH & pCO2 & pO2 & $\mathrm{HCO3}$ & TCO2 & ABE & SBE & SBC & SAT \\
\hline Thermic $\mathrm{T}_{0}$ & $\mathrm{~ns}$ & $\mathrm{~ns}$ & 0,01 & $\mathrm{~ns}$ & tend & 0,05 & 0,05 & 0,01 & tend & $\mathrm{ns}$ \\
\hline Magnetic $T_{0}$ & tend & ns & 0,01 & 0,01 & 0,01 & 0,01 & 0,05 & 0,05 & 0,05 & 0,05 \\
\hline Magnetic $T_{1}$ & ns & ns & ns & ns & tend & tend & 0,05 & 0,05 & 0,05 & ns \\
\hline Magnetic $T_{2}$ & 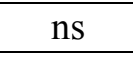 & ns & 0,05 & 0,01 & 0,05 & 0,01 & 0,01 & 0,01 & 0,05 & 0,01 \\
\hline \multirow[t]{2}{*}{ Test } & \multicolumn{10}{|c|}{ Venous $(p<)$} \\
\hline & Temp. & pH & pCO2 & pO2 & $\mathrm{HCO} 3$ & TCO2 & ABE & SBE & SBC & SAT \\
\hline Thermic $\mathrm{T}_{0}$ & ns & $\mathrm{ns}$ & ns & 0,05 & ns & ns & ns & ns & ns & 0,05 \\
\hline Magnetic $T_{0}$ & tend & $\mathrm{ns}$ & 0,05 & ns & 0,01 & 0,01 & 0,01 & 0,01 & 0,01 & ns \\
\hline Magnetic $T_{1}$ & ns & 0,05 & ns & 0,05 & ns & ns & ns & ns & ns & ns \\
\hline Magnetic $T_{2}$ & ns & & ns & 0,05 & ns & ns & ns & ns & ns & ns \\
\hline
\end{tabular}

Test results of the effects of electromagnetic therapy in horses using magnetic blanket

It is reasonable to raise the question whether significant changes can be detected between two treatments or between the control and the treatment. Which are the temporary changes to which horses respond really sensibly? This is the reason why we applied paired t-test. The results are summed up in Table 2. The results show that no significant changes can be detected with the use of magnetic blanket as far as the tested blood parameters are concerned. Blood and SAT reflect the change of the state of horses under stress. It is worth noting that horses give significant responses in their physical parameters (pulse, SAT) to such events as placing on and taking off the magnetic blanket or drastic stress. 
Table 2. Test results of the effects of electromagnetic therapy in horses based on comparison between control and treated as well as treated and treated groups, where $n s=$ non significant and tend $=$ tendency.

\begin{tabular}{|l|c|c|c|c|c|c|c|c|}
\hline & I. & II. & III. & IV. & V. & VI. & VII. & VIII. \\
\hline Pulse & $\mathrm{ns}$ & 0,05 & $\mathrm{~ns}$ & 0,01 & $\mathrm{~ns}$ & 0,05 & $\mathrm{~ns}$ & $\mathrm{~ns}$ \\
\hline Resp. & $\mathrm{ns}$ & $\mathrm{ns}$ & tend & tend & $\mathrm{ns}$ & $\mathrm{ns}$ & $\mathrm{ns}$ & $\mathrm{ns}$ \\
\hline Temp. & $\mathrm{ns}$ & $\mathrm{ns}$ & $\mathrm{ns}$ & $\mathrm{ns}$ & $\mathrm{ns}$ & $\mathrm{ns}$ & $\mathrm{ns}$ & $\mathrm{ns}$ \\
\hline pH & 0,01 & tend & 0,01 & $\mathrm{~ns}$ & $\mathrm{~ns}$ & tend & $\mathrm{ns}$ & $\mathrm{ns}$ \\
\hline pO $_{2}$ & tend & $\mathrm{ns}$ & 0,05 & $\mathrm{~ns}$ & $\mathrm{~ns}$ & $\mathrm{~ns}$ & $\mathrm{~ns}$ & $\mathrm{~ns}$ \\
\hline $\mathbf{p C O}_{2}$ & $\mathrm{~ns}$ & $\mathrm{~ns}$ & $\mathrm{~ns}$ & $\mathrm{~ns}$ & $\mathrm{~ns}$ & $\mathrm{~ns}$ & $\mathrm{~ns}$ & $\mathrm{~ns}$ \\
\hline HCO $_{3}$ & $\mathrm{~ns}$ & $\mathrm{~ns}$ & $\mathrm{~ns}$ & $\mathrm{~ns}$ & tend & $\mathrm{ns}$ & $\mathrm{ns}$ & $\mathrm{ns}$ \\
\hline Saturation & $\mathrm{ns}$ & 0,05 & 0,05 & $\mathrm{~ns}$ & $\mathrm{~ns}$ & 0,05 & $\mathrm{~ns}$ & $\mathrm{~ns}$ \\
\hline
\end{tabular}

\section{Results of the effects of electromagnetic therapy on the biochemical parameters using magnetic blanket}

Table 3 contains the results of paired t-test before and after electromagnetic field treatments. It is obvious from the table that the biochemical parameters show significant deviations on day 1 , day 2 and day 5 . There is no change on day 4 .

Table 3. Results of the effects of electromagnetic therapy on the biochemical parameters $L D H$, AST and $C K$, where ns=non significant and tend=tendency.

\begin{tabular}{|l|c|c|c|c|c|}
\hline & Day 1 & Day 2 & Day 3 & Day 4 & Day 5 \\
\hline LDH & ns & 0,01 & 0,05 & ns & ns \\
\hline AST & 0,05 & 0,001 & ns & ns & 0,05 \\
\hline CK & 0,05 & $n s$ & $n s$ & $n s$ & 0,05 \\
\hline
\end{tabular}

We might suppose that magnetic therapy affects the immune system of animals. On the first two days of magnetic field therapy the organism gives a natural response to the electromagnetic field therapy and the tested parameters show significant deviations. In the meantime, the organism attempts to compensate the magnetic field effect and on day 4 it protects itself from the inconvenient external effect. From day 5 the inconvenient external effect appears again, which the immune system attempts to compensate periodically or in some other way. Longer period (months) would be required to justify our hypothesis. Namely, that protracted, consequently carried out electromagnetic field therapy would lead to the impairment of the immune system.

We note that when one is applying paired t-test and making several pairwise comparisons, the error of first kind may be increased. We plan a detailed analysis of experiments on representative samples, one- and two-way (repeated measures) analysis of variance models.

\section{Conclusion}

Comparing human and veterinary biological results we can state that the effects of electromagnetic field are expressed latently, but have significant biological effects and consequencies. Special attention should be paid to the electromagnetic protection of the 
environment. It is an urgent task to learn about the effect mechanism of electromagnetic radiation having noxious or therapeutic effect in the field of both human and veterinary biology.

Acknowledgement. Authors thank Horst Leopold and Wallner (Med Tech Produktions- und Vetriebs $\mathrm{GmbH}$, Linz, Austria) for providing the MCR Vet electromagnetic field set.

\section{REFERENCES}

[1] Adams, J.M., Cary, S. (1991): Transgenic models of tumor development. - Science 254:1161-1167.

[2] Ahlborn, A., Feychting, M. (1993): Magnetic fields and cancer in children residing near Swedish high-voltage power lines. - Am. Jur. Epidemiol. 138:467-481.

[3] Barnothy, M.F. (1964): Biological Effects of Magnetic fields. - Pelnum Press, New York (51 p.)

[4] Börzsönyi, L., Fodor, J., Varga, J., Szenci, O. (2004): Biometrical characterization of blood gas and acid-base parameters in newborn calves in the postpartal period. - 25th Annual Conference The International Society for Clinical Biometrics, Leiden, (145 p.)

[5] Hamrick, P.E., Fox, S.S. (1977): Rat lymphocytes in culture exposed to $2450 \mathrm{MHz}$ (CW) microwave radiation. - J. Microwave Power 12: 125-132.

[6] Hoffsis, G.F., Murdich, P.W., Tharp, V.L., Ault, K. (1970): Plasma concentration of cortisol and corticosterone in the normal horse. - Am. J. Vet. Res. 31: 1379-87.

[7] Maurino, RM. (1991): From Thales to Lauterbut, or from Iodestone to MR imaging: magnetism and medicine. - Radiology; 180: 593-612.

[8] Ieran, M. (1990): Effect of low frequency pulsing electromagnetic fields on skin ulcers of venous origin in humans: A double blind study. - J. Orthop. Res. 8: 276-282.

[9] Kobluk, C.N., Johnston, G.R., Lauper, L. (1994): A scintigraphic investigation of magnetic field therapy on the equine third metacarpus. - Vet. Comp. Orth. Traum. 7: 9-13.

[10] Kósa, L., Börzsönyi, L. (1999): Napjaink allergiái és biostatistika - Allergy Today and Biostatistics. - CD-ROM, AUTOMEX, CYBERTSTONE, TRANS-EUROPE Kft, Budapest, (350 p.)

[11] Lozán, J.L., Kausch, H. (1998): Angewandte Statistik für Naturwissenschaftler. - Parey Buchverlag, Berlin (152 p.)

[12] Mátay, G., Zombory, L. (2003): A rádiófrekvenciás sugárzás élettani hatásai és orvosbiológiai alkalmazásai (Physiological effects and human biological applications of radiofrequency radiation; Book in Hungarian). - Müegyetemi Kiadó, Budapest.

[13] Polk, Ch. Postow, E. (1996): Handbook of Biological Effects of Electromagnetic Field CRC - Press, Boca Raton, New York, London (112 p.)

[14] Ramsey, P.H. (1980): Exact type I error rates for robustness of Student's T test with unequal variances. - Journal of. Educational Stat. 5: 337-49.

[15] Ramey, D.W. (1999): Magnetic and electromagnetic therapy in horses. - Compendium on Continuing Education for the Practicing Veterinarian. 21: 553-560.

[16] Rasch, D., Herrendörfer, G., Bock, J., Victor., Guiard, V. (1996): Verfahransbibliothek Versuchsplanung- und -ausertung. - R. Oldenburg Verlag, München Wien, 433 p., 847 p.)

[17] Repacholi, M.H., Basten, A., Gebski, V., Nooman, D., Finnie, J., Harris A. W. (1997): Lyphomas in E $\mu$-Pim1 transgenic mice exposed to pulsed $900 \mathrm{Mhz}$ elektromagnetic Filds. Radiation Research. 147: 631-640.

[18] Steyn, P.F., Ramey, D.W., Kirschvink, J., Uhrig, J. (2000): Effect of a static magnetic field on blood flow to the metacarpus in horses. - J. Am. Vet. Med. Ass. 217: 6, 874-877.

[19] Varga, A. (1999): Elektrosmog. Ein wissenschaftlich begründeter und biologisch wirksamer Umweltfaktor. - The Journal of Natural Science 2: 50-55. 
[20] Varga, A. (2002): Grundlage des Elektrosmogs in Bilder. - Verlag Umweelt + Medizin, Heidelberg (114 p.)

[21] Wilcox, R.R.: (2001): Fundamental of modern statistical methods. - Springer-Verlag, New York, Inc. (84 p.)

[22] Zombory, L. (2005): Electromagnetic protection of the environment (lecture in Hungarian)

[23] Zombory, L., Mátay, G. (2005): Physiological effects and human biological applications of radiofrequency radiation. (Book in Hungarian, in press) 